Cite as: P. Lan et al., Science

10.1126/science.abc0149 (2020).

\title{
Structural insight into precursor ribosomal RNA processing by ribonuclease MRP
}

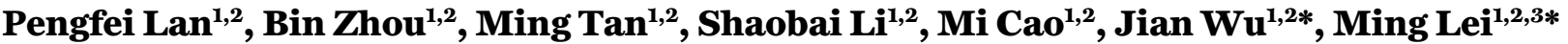 \\ ${ }^{1}$ State Key Laboratory of Oncogenes and Related Genes, Ninth People's Hospital, Shanghai Jiao Tong University School of Medicine, Shanghai 200011 , China. \\ ${ }^{2}$ Shanghai Institute of Precision Medicine, Shanghai 200125, China. ${ }^{3}$ Key Laboratory of Cell Differentiation and Apoptosis of Chinese Ministry of Education, \\ Shanghai Jiao Tong University School of Medicine, Shanghai 200025, China. \\ *Corresponding author. Email: leim@shsmu.edu.cn (M.L.); wujian@shsmu.edu.cn (J.W.)
}

\begin{abstract}
Ribonuclease (RNase) MRP is a conserved eukaryotic ribonucleoprotein complex that plays essential roles in pre-ribosomal RNA (pre-rRNA) processing and cell cycle regulation. In contrast to RNase $\mathrm{P}$, which selectively cleaves tRNA-like substrates, it has remained a mystery how RNase MRP recognizes its diverse substrates. To address this question, we determined cryo-EM structures of Saccharomyces cerevisiae RNase MRP alone and in complex with a fragment of pre-rRNA. These structures combined with biochemical studies reveal that co-evolution of both protein and RNA subunits has transformed RNase MRP into a distinct ribonuclease that processes single-stranded RNAs by recognizing a short, looselydefined consensus sequence. This broad substrate specificity suggests that RNase MRP may have myriad yet unrecognized substrates that could play important roles in various cellular contexts.
\end{abstract}

Ribonuclease mitochondrial RNA processing (RNase MRP) is an essential eukaryotic ribonucleoprotein (RNP) that cleaves RNA substrates in a site-specific manner and plays pivotal roles in RNA metabolism (1-3). Its importance is manifested by the fact that a proteinaceous endoribonuclease that can cleave RNAs with sequence specificity has not been found in nature (4). RNase MRP is structurally and evolutionarily closely related to RNase $\mathrm{P}$, another essential RNase that catalyzes the maturation of the $5^{\prime}$-end of precursor-transfer RNA (pre-tRNA) (3, 5-8). In contrast to RNase P, RNase MRP processes much more diversified substrates. Saccharomyces cerevisiae RNase MRP is predominantly localized in the nucleolus, where it is responsible for precursor ribosomal RNA (pre-rRNA) processing at a specific A3 site in the internal transcribed spacer region 1 (ITS1) to release the mature 5.8S rRNA (9-12). S. cerevisiae RNase MRP also asymmetrically and temporally exists in a single discrete cytoplasmic spot in daughter cells, where it regulates the cell cycle by cleaving the $5^{\prime}$-UTR of the cyclin B2 (CLB2) mRNA $(13,14)$. Similar roles of human RNase MRP in ribosome assembly and cyclin-dependent cell cycle regulation have also been established $(15,16)$. Several protein subunits of human RNase MRP have been considered immunological targets in autoimmune diseases (17-19), and mutations in the RNA subunit of human RNase MRP (RMRP) cause a spectrum of severely debilitating human diseases, including cartilage-hair hypoplasia $(\mathrm{CHH})(20,21)$, underscoring RNase MRP's essential role in human health.
RNase MRP holoenzyme contains a large catalytic RNA and multiple essential proteins $(22,23)$. Except for one or two species specific proteins, the catalytic RNA and most of the protein subunits of RNase MRP are conserved from yeast to humans (3). In S. cerevisiae RNase MRP, the majority of the protein components are shared with $S$. cerevisiae nuclear RNase P with the exception of Rmpl and Snm1 (3, 22). Previous secondary structure analyses predicted that the RNA component of $S$. cerevisiae RNase MRP (Nmel) has a similar RNase P-type catalytic (C) domain (24-26). In particular, key nucleotides in the predicted active center highly resemble those in RNase P RNA, suggesting that both ribozymes likely share the same catalytic mechanism $(3,27)$. In sharp contrast to the $\mathrm{C}$ domain, the rest of the Nme1 RNA is completely different from the specificity (S) domain of RNase P RNA (3). In fact, it is even not clear whether this part of Nme1 is involved in the specific recognition of substrates. It has been speculated that this diversified RNA region and specific protein components of RNase MRP have been co-evolved during evolution, giving rise to altered substrate specificity $(28,29)$. Despite extensive biochemical and genetic studies, the lack of high-resolution structure of RNase MRP severely hinders our understanding of how this essential RNP could process such diversified substrates as pre-rRNA and CLB2 mRNA.

Here we present the cryo-electron microscopy (EM) structures of $S$. cerevisiae RNase MRP holoenzyme alone and in complex with an ITS1 fragment containing the A3 
cleavage site. These structures reveal that, although the catalytic center of RNase MRP is nearly identical to that in RNase $\mathrm{P}$, a striking local refolding of key protein subunits transforms RNase MRP into a distinct ribonuclease to process single-stranded RNAs by recognizing a short consensus sequence.

\section{Characterization of $S$. cerevisiae RNase MRP holoenzyme}

We purified the endogenous RNase MRP holoenzyme from $S$. cerevisiae using a two-step affinity purification scheme with a protein-A tag on subunit Pop4 and a triple-Flag tag on the RNase MRP-specific subunit Rmp1, the latter of which effectively prevented the contamination from RNase P (fig. S1A) $(30,31)$. The purified RNase MRP complex was subjected to mass spectrometry analysis, confirming the presence of all previously identified protein components in S. cerevisiae RNase MRP (fig. S1, A and B, table S1, and supplementary materials and methods).

The purified RNase MRP holoenzyme was fully active to process a 123-nucleotide (nt) ITS1 fragment of yeast prerRNA containing the A3 site with no detectable activity to pre-tRNA (Fig. 1A and fig. S1C) $(10,32)$. Sequence and phylogenetic analysis of ITS1 regions from multiple species in Saccharomycetaceae revealed a highly conserved 12-nt fragment containing the A3 cleavage site with a GC-rich stem and a long stretch of AU-rich sequence at its $5^{\prime}$ and $3^{\prime}$ termini, respectively (Fig. $1 \mathrm{~B}$ and fig. S2). Notably, neither the stem nor the AU-rich sequence is required for the substrate recognition by RNase MRP (Fig. 1A and fig. S3). Further experiments showed that a 21-nt fragment with the A3 site at the center can be efficiently processed by RNase MRP (Fig. 1A and fig. S3), suggesting that, unlike RNase P, which recognizes the three-dimensional structural feature of pretRNA, RNase MRP processes short, single-stranded substrates with a distinct sequence specificity (Fig. 1A and fig. S3). This is consistent with a previous in vitro selection of $S$. cerevisiae RNase MRP substrates (32). Hereafter, we will refer to this 21-nt fragment as $\mathrm{ITS1}_{\mathrm{A} 3}$ (Fig. 1A). For simplicity, we define the nucleotide $3^{\prime}$ to the cleavage site as the "center" (position 1) of $\operatorname{ITS1}_{\mathrm{A} 3}$ (Fig. 1A).

\section{Structures of RNase MRP and its complex with the ITS1 $_{\text {A3 }}$ substrate}

To gain insights into the architecture of RNase MRP and the molecular basis of substrate recognition by RNase MRP, we determined the cryo-EM structures of $S$. cerevisiae RNase MRP holoenzyme alone and its complex with the ITS1 $1_{\mathrm{A} 3}$ substrate at resolutions of $2.5 \AA$ and $2.9 \AA$, respectively (Fig. 1, C and D, fig. S4, and table S2). The cryo-EM density maps were of sufficient quality, enabling us to build the atomic model of RNase MRP (Fig. 1, C and D and fig. S5, A to C).
Nucleotides $\mathrm{A}(-2)$ to $\mathrm{A} 5$ in the $\mathrm{ITS}_{\mathrm{A} 3}$ substrate were clearly discernable in the density map (fig. S5D). In addition, the EM map also revealed a stacking of the bases of A6 and A7 with $\mathrm{A} 5$, allowing us to generate a model of $\mathrm{ITS1}_{\mathrm{A} 3}$ containing nine continuous nucleotides $\mathrm{A}(-2)$ to $\mathrm{A} 7$ (Fig. 1D and fig. S5D). The structure of apo RNase MRP can be superimposed onto that of the RNase MRP-ITS1 $1_{\mathrm{A} 3}$ complex with a root mean square deviation (RMSD) value of $\sim 0.5 \AA$ (fig. S6A), suggesting that RNase MRP adopts a rigid conformation before substrate binding. Hereafter we will focus on the RNase MRP-ITS1 $1_{\mathrm{A} 3}$ complex structure, unless stated otherwise.

In the RNase MRP holoenzyme, the Nme1 RNA forms a compact structure occupying the central region of the complex (Fig. 1C). Eleven protein subunits sequentially contact one another and interlink together to form a hook-shaped architecture, with Pop1, Rmp1, and part of Pop4 as the head, and Pop6-Pop7, Pop5-(Rpp1) $)_{2}$-Pop8, and Pop4-Snm1-Pop3 subcomplexes being the arm (Fig. 1C). This protein hook tightly wraps around and stabilizes Nme1, involving intricate interactions between Nme1 and the protein head module at one side and an extended, flat interface between Nmel and the arm module at the other (Fig. 1C). Together, these RNA-protein interactions shape the holoenzyme into a configuration with a deep, narrow groove at the catalytic center, in which snugly lies the single-stranded $\mathrm{ITS}_{\mathrm{A} 3}$ substrate (Fig. 1D). The Pop1-Pop4-Rmp1 ternary motif in the head module mediates specific interactions with the substrate (Fig. 1D). The EM density map of this ternary motif is well-ordered in the complex, but it is of poor quality in the apo structure, suggestive of a local induced fit mechanism for substrate recognition by RNase MRP (fig. S6B). It is noteworthy that the $\mathrm{ITS1}_{\mathrm{A} 3}$-binding surface on the Pop1Pop4-Rmp1 motif is highly conserved in Saccharomycetaceae, underscoring the important function of this ternary motif in substrate recognition (fig. S7, A to C).

\section{Structure of the Nme1 RNA}

The Nme1 RNA adopts an extended single-layered configuration with a compact core from which extend out four stems P3 ', P10, P11 and P15 to different directions (Fig. 2, A and $\mathrm{B}$ ). The RNA core is characterized by three parallelly packed helices, which are composed of coaxially stacked stems P19-P2-P3, P1-P4 and P9-P8, respectively (Fig. 2, A and B). Except for the tip of P19, helices P19-P2-P3 and P1-P4 highly resemble their counterparts in the RNase $\mathrm{P}$ structure (fig. S8, A and B) $(30,33)$. In particular, three conserved regions CR-I, CR-IV and CR-V in the core of Nmel fold into a pseudoknot motif, which is identical to the structure observed in the catalytic center of RNase P (fig. S8, A and B) (30, 34-37).

Previous sequence analyses predicted a long stem ymP5 
in the Nme1 RNA, but failed to assign it as the P9 stem in that the predicted ymP5 contains a much longer duplex than P9 normally has in RNase P $(3,25,26)$. Therefore, it was unanticipated that stems P8 and P9 in the S domain of Nme1 could coaxially stack together to form a continuous helix in the RNA core with a duplex region that resembles helix P9-P8 in the RNase P structure (fig. S8, B and C). In fact, the P9 stem in Nme1 contains a very large loop, part of which (U132-A136) is disordered and the rest folds back to its own minor groove and mediates non-Watson-Crick interactions with three consecutive base pairs A121-U153, G122-C152 and A123-A151 (fig. S8, C and D), allowing P9 to contact P1 in the same fashion as in RNase P (fig. S8, B and C). Similarly, on the other end of the P9-P8 helix, the pentaloop of stem P8 ( ${ }_{109} \mathrm{GAAAA}_{113}$ ) that corresponds to previously identified consensus sequence GARAR (R: purine) in RNase MRP RNAs interacts with the minor groove of stem P4, closely resembling the P8-P4 interface in RNase P RNA (fig. S8, B and C) (30). Together, we conclude that the compact RNA core with three parallelly packed helices is conserved in both RNase MRP and RNase P RNAs (Fig. 2A and fig. S8, A and B) (30). In addition to stem P9, the structure of Nme1 also reveals a three-base-pair stem P5 immediately adjacent to $\mathrm{P} 4$, which has not been predicted by previous analyses but is very likely conserved in all RNase MRPs (Fig. 2, A and B) $(3,25-27)$.

Except for the P9-P8 helix, the rest of the S domain in Nmel (stems P10 and P11, previously named as ymP6 and ymP7) is markedly different from the $\mathrm{S}$ domain in RNase $\mathrm{P}$ RNA (fig. S8E), and only makes very limited contacts with protein subunits in RNase MRP (Fig. 1C). Both P10 and P11 can be considerably reduced in size without significant effects on viability or pre-rRNA processing in vivo, indicating that these stems are not critical for RNase MRP function (38). This is in sharp contrast to the P10/11-P12 branch of the RNase P RNA in which conserved regions CR-II and CRIII fold into a T-loop structure and play an important role in pre-tRNA substrate binding (fig. S8, A and B) $(30,39,40)$. Collectively, we conclude that the S domain of Nme1 is distinct from its counterpart in RNase P RNA both structurally and functionally.

\section{Protein subunits and their interactions with Nme1}

The overall architecture of the protein hook in RNase MRP resembles that of RNase $P$ (fig. S9A). In particular, the Pop6-Pop7 heterodimer, the Pop5-(Rpp1) $)_{2}$-Pop8 heterotetramer, and the Pop4-Snm1-Pop3 heterotrimer are identical to their counterparts in RNase P (fig. S9, A to D) (30, 33, 41). These three protein subcomplexes together form an elongated arm and cover the surface of one side of the Nme1 RNA (Fig. 1C and fig. S9A). The protein head module contains Pop1, Rmp1 and the N-terminal motif of Pop4
(Pop4 $4_{\mathrm{NTM}}$ ) (Fig. 3A). Pop1, the largest protein subunit in both RNase MRP and RNase P, is composed of three motifs: an $\mathrm{N}$-terminal motif (NTM), an internal motif (INM), and a large C-terminal globular domain (CTD) (Fig. 3A). Pop1 $1_{\text {СтD is }}$ separated from the rest of the head module, covering the RNA core in the same fashion as in RNase P from the other side of the RNA opposite to the arm module (Fig. 3A and fig. S9E).

Notwithstanding these similarities, marked structural differences do exist in both the RNA and protein subunits in the vicinity of the substrate-binding site. In RNase $P$, Pop1 $1_{\text {NTM }}$ adopts a helical structure enriched with positively charged residues to stabilize the open junction between CRIV, stems P4, P7 and P15 of the Rpr1 RNA, serving as an anchor for pre-tRNA substrate recognition (Fig. 3B and fig. S10, A and B) (30). Pop4 $4_{\mathrm{NTM}}$, on the contrary, folds into a small compact motif and binds the Rpr1 RNA from the opposite side of Pop1 $1_{\mathrm{NTM}}$ (Fig. 3B and fig. S10, A and C) (30). Strikingly, in RNase MRP, both Pop1 $1_{\text {NTM }}$ and Pop4 $4_{\text {NTM }}$ completely refold themselves and adopt extended conformations, wrapping around one end of the helix bundle of Rmp1 (Fig. 3B and fig. S11, A to D). This intricate ternary subcomplex sits atop stem P5 and mediates intimate interactions with the pseudoknot of Nmel, forming part of the substrate-binding groove and playing an important role in specific recognition of single-stranded substrates (Fig. 3B). It should be noted that, although Pop1 $1_{\mathrm{NTM}}$ adopts completely different conformations in RNase MRP and RNase P, a short stretch of arginine residues (R94, R97, R98 and R99) occupies exactly the same location and mediates similar stacking and electrostatic interactions with the RNA pseudoknot, underscoring the crucial function of these residues in stabilizing the catalytic center in both RNPs (fig. S12, A and B) (30). In addition to Pop1 $1_{\mathrm{NTM}}$, Pop1 $1_{\mathrm{INM}}$ in RNase MRP also reorganizes itself with a distinct fold, sitting in a deep cleft formed by the junction among stems P5 and P8 to P11 (Fig. $3 \mathrm{~B}$ and fig. S11B). In comparison, Pop1 ${ }_{\mathrm{INM}}$ in RNase $\mathrm{P}$ forms a different topology and associates with the P7-P8' '-P8-P9P10/11 junction from the opposite direction. (Fig. 3B and fig. S10B) (30).

Another distinct structural feature of RNase MRP occurs at the interface between stem P9 of Nmel and the Pop4-Snm1-Pop3 heterotrimer. In both RNase P and RNase MRP, a long helix of Pop4 simultaneously associates with the termini of stems P1 and P9, enhancing the long-range RNA-RNA interactions (Fig. 3C). In RNase MRP, Pop4 ${ }^{\text {Tyr78 }}$ in the helix mediates a stacking interaction with nucleotide U125 of Nme1, stabilizing the loop of stem P9 in a folded conformation (Fig. 3C). This in turn allows the Pop4 helix to maintain its direction so that it can be connected to Pop4 $4_{\mathrm{NTM}}$ in the head module for substrate recognition (Fig. 3C). By contrast, in RNase P the local structure of Rpr2 and the 
bulge in stem P9 change the direction of Pop4 helix with a sharp turn of $\sim 90^{\circ}$, which otherwise would have a severe collision with the T-loop of the RNA if the helix adopts the same continuous conformation as in RNase MRP (Fig. 3D). Furthermore, the folded loop in stem P9 in RNase MRP occupies the location of the $\mathrm{T} \psi \mathrm{C}$ loop of pre-tRNA in the RNase $\mathrm{P}$ complex, indicating that pre-tRNA could not fit into the substrate-binding site in RNase MRP (Fig. 3E). Taken together, we conclude that, although RNase MRP shares the same overall structural organization as RNase P, several key structural differences in both protein and RNA subunits define RNase MRP as a distinct ribozyme to process nonpre-tRNA substrates.

\section{The RNase MRP-ITS1 $1_{\mathrm{A} 3}$ interface}

Although $\mathrm{ITS1}_{\mathrm{A} 3}$ is a single-stranded substrate, it adopts a helical-like conformation, resembling the $5^{\prime}$ strand of the pre-tRNA acceptor stem in the RNase P complex (fig. S13, A and $\mathrm{B})$. $\mathrm{ITS1}_{\mathrm{A} 3}$ is accommodated deeply in the substratebinding site, sitting on the minor groove of stem $\mathrm{P} 4$ in the Nme1 pseudoknot with its backbone partially or completely buried in a solvent-excluded contact area of $\sim 1,200 \AA^{2}$ (Fig. $4 \mathrm{~A})$. The overall conformation of the $\mathrm{ITSl}_{\mathrm{A} 3}$ substrate is mainly governed by two sets of the $\pi-\pi$ stacking interactions among bases; $\mathrm{A}(-2)$ stacks with $\mathrm{A}(-1), \mathrm{A} 1$ and $\mathrm{C} 2$, and $\mathrm{A} 3$ with A5, A6 and A7 (Fig. 4, A and B). The A(-2)-A(-1)-A1-C2 stack is further extended into the Nmel RNA by the base of U266 in CR-IV of Nmel (Fig. 4, A to C). Notably, this intermolecular continuous base stack highly resembles the stacking between the 5 '-leader of pre-tRNA and nucleotide A314 in CR-IV of the Rpr1 RNA in the RNase P-pre-tRNA complex structure (Fig. 4C and fig. S13, C and D) (30). In addition to the stacking, the sugar-ring and the phosphate backbone of $\mathrm{A}(-1)$ in $\mathrm{ITS1}_{\mathrm{A} 3}$ mediate two electrostatic interactions with the main chain of Pop5 N-terminal residue Val2 (Fig. 4C and fig. S13C), which are also conserved in the RNase P-pretRNA interactions (fig. S13D) (30). Together, these observations indicate that both RNase MRP and RNase P utilize the same molecular mechanism to non-specifically bind nucleotides of the substrates $5^{\prime}$ to the cleavage site (fig. S13, A to D) (30).

The most prominent features of the $\mathrm{ITS1}_{\mathrm{A} 3}$ substrate are the two cytosine, $\mathrm{C} 2$ and $\mathrm{C} 4$, that define the sequence-specific recognition of $\mathrm{ITSl}_{\mathrm{A} 3}$ by RNase MRP. The side chain of Pop4 ${ }^{\mathrm{Ar} 28}$ points to the ITS1 ${ }_{\mathrm{A} 3}$ substrate and coordinates two electrostatic interactions with the Watson-Crick donor and acceptor groups of $\mathrm{C} 2$ in $\mathrm{ITS1}_{\mathrm{A} 3}$ (Fig. 4, B and D and fig. $\mathrm{S} 13 \mathrm{E})$. When the RNase MRP-ITS1 $1_{\mathrm{A} 3}$ structure is overlaid onto that of the RNase P-pre-tRNA complex, the short helix in Pop4 $4_{\mathrm{NTM}}$ occupies the equivalent position of pre-tRNA G71-C72 in the RNase P-pre-tRNA complex and the C2Pop$^{\mathrm{Arg} 28}$ interaction strikingly mimics the C2-G71 base pair- ing in pre-tRNA, stabilizing the single-stranded $\operatorname{ITS1}_{\mathrm{A} 3}$ in the helical conformation (fig. S13, E and F) (30). This Pop4 ${ }^{\mathrm{Arg} 28}$ mediated 'pseudo-Watson-Crick' interaction together with a hydrogen bond between the sugar-ring hydroxyl group of C2 and the side chain of Rmp1 ${ }^{\mathrm{Gln} 97}$ prefers a cytosine at position 2 in the $\mathrm{ITS1}_{\mathrm{A} 3}$ substrate (Fig. 4, B and D). In addition to the interaction with $\mathrm{C} 2$, the guanidino group of Pop4 ${ }^{\mathrm{Arg} 28}$ also makes a stacking interaction with the base of A3, serving as a stabilizing connector between $\mathrm{C} 2$ and A3 (Fig. 4, B and D).

In contrast to $\mathrm{C} 2, \mathrm{C} 4$ flips out from the helical position and points into a pocket formed by the protein head module and the Nme1 RNA (Fig. 4, B and E, and fig. S13G). The base of $\mathrm{C} 4$ is sandwiched by the side chains of $\mathrm{Rmpl}^{\mathrm{Arg} 24}$ and $\mathrm{Pop}^{\mathrm{His} 103}$ through stacking interactions in the center of the pocket (Fig. 4, B and E). The structure shows that the cavity of the pocket is not optimal to accommodate bulky purine nucleotides (Fig. 4E). Notably, the edge of the base of $\mathrm{C} 4$ is surrounded with three hydrogen-bonding interactions with Nme1 U226, Rmp1 ${ }^{\mathrm{Ar} 24}$ and Pop4 ${ }^{\mathrm{Thr} 38}$, providing a strong preference for cytosine at this position (Fig. 4E). In addition to these sequence specific interactions, the backbone phosphate group of $\mathrm{C} 4$ accepts one hydrogen bond from $\mathrm{Rmp}^{\mathrm{Gln} 28}$, further stabilizing the base of $\mathrm{C} 4$ in the pocket (Fig. 4E). Collectively, the RNase MRP-ITS1 $1_{\mathrm{A} 3}$ complex structure demonstrates that RNase MRP recognizes a short single-stranded region of $\mathrm{ITS1}_{\mathrm{A} 3}$ and two nucleotides $\mathrm{C} 2$ and $\mathrm{C} 4$ make sequence specific interactions with RNase MRP.

\section{Consensus substrate sequence}

To further define the consensus substrate sequence for RNase MRP, we mutated each nucleotide from $\mathrm{C}(-3)$ to $\mathrm{A} 5$ in $\mathrm{ITS}_{\mathrm{A} 3}$ and evaluated their effects using the in vitro activity assay. Consistent with the structure, substitution of $\mathrm{C} 4$ with any other nucleotides all led to reduced activity, confirming that position 4 relative to the cleavage site prefers a cytosine (Fig. 4F) (32). In contrast to C4, mutational analysis of $\mathrm{C} 2$ resulted in a hierarchical ranking of $\mathrm{C}>\mathrm{U}>\mathrm{A}>\mathrm{G}$, from the most to the least preferred nucleotide for position 2 in $\mathrm{ITS1}_{\mathrm{A} 3}$ (Fig. 4F). Notably, this nucleotide ranking is in perfect agreement with the RNase MRP-ITS1 $1_{\mathrm{A} 3}$ interface at C2. First, despite the shape of uracil resembling cytosine, its imino group does not provide compatible hydrogen bond acceptors to the guanidino group of Pop4 ${ }^{\mathrm{Arg} 28}$ (Fig. 4D). Second, due to the small size of the pocket, a pyrimidine is preferred at position 2 (Fig. 4D). Third, if a purine could be fit into position 2 by some local structural adjustment, adenine is more favorable than guanine due to the same consideration of hydrogen bond compatibility with the side chain of Pop4 $4^{\mathrm{Arg} 28}$ (Fig. 4D).

In accordance with the observation that nucleotides other than $\mathrm{C} 2$ and $\mathrm{C} 4$ in $\mathrm{ITS1}_{\mathrm{A} 3}$ make no sequence specific interactions with RNase MRP, single nucleotide replace- 
ment at positions $-3,-2,-1$, or 5 in $\mathrm{ITS}_{\mathrm{A} 3}$ had marginal effect on the processing activity of RNase MRP (Fig. 4F). Surprisingly, substitution of A1 or A3 with a uracil or cytosine led to a detectable reduction in activity (Fig. 4F). Close examination of complex structure suggested that the stacking interaction between A3 and the guanidino group of Pop4 ${ }^{\mathrm{Arg} 28}$ will likely be weakened by a pyrimidine replacement of A3 (Fig. 4F). Similarly, a pyrimidine at position 1 would also attenuate the stacking interaction with C2 (Fig. 4F). Therefore, the mutational data are consistent with the structural information, suggestive of a preference for purines for positions 1 and 3 in the substrate. In aggregate, combination of our structural and biochemical data defines a short consensus sequence for RNase MRP substrate as $5^{\prime}$ - $^{*} \mathrm{RCRC}-3^{\prime}$ (*: cleavage site). Notably, an A-to-C substitution at position -1 would generate two additional optimal cleavage sites between positions -5 and -4 and between -3 and -2 (Fig. 1A). Indeed, the activity assay of this mutant $\operatorname{ITS}_{\mathrm{A} 3}$ substrate generated three equal-amount products with the expected sizes (Fig. 4F), providing an independent validation of the consensus sequence for RNase MRP substrates.

It should be noted that there was a minor band below the consensus product in the in vitro assay, indicating a cleavage event between $\mathrm{A}(-5)$ and $\mathrm{A}(-4)$ in $\mathrm{ITS1}_{\mathrm{A} 3}$ using $5^{\prime}$ *ACAA-3' as the substrate recognition sequence (Fig. 4F). This is in agreement with the mutational data that the majority of the single-nucleotide substitutions in $\operatorname{ITS}_{\mathrm{A} 3}$ were not deleterious and can still be cleaved by RNase MRP (Fig. $4 \mathrm{~F})$. In addition to $\mathrm{ITSl}_{\mathrm{A} 3}$, several substrates of yeast RNase MRP have been identified, and among them the cleavage regions in the $5^{\prime}$-UTRs of CLB2 mRNA and chitinase CTS1 mRNA have been biochemically characterized $(13,42)$. In light of the RNase MRP-ITS1 ${ }_{\mathrm{A} 3}$ structure, we performed multiple sequence alignment of these cleavage regions. The resulting cleavage sequences of this alignment largely abides by the $5^{\prime}-^{*} \mathrm{RCRC}-3^{\prime}$ rule derived from the structural and mutational analysis of the RNase MRP-ITS1 ${ }_{\mathrm{A} 3}$ interaction yet with some exceptions (fig. S14), suggesting that, despite the preferred $5^{\prime}$-*RCRC-3' substrate sequence, RNase MRP can still process a broader spectrum of single-stranded RNA substrates.

\section{Active site}

The cryo-EM density map unveils three putative metal ions (M1, M2 and M3) in the vicinity of the scissile phosphate, which would stabilize the $\mathrm{ITSl}_{\mathrm{A} 3}$ substrate at the catalytic center of RNase MRP (fig. S15, A and B). The EM density map is of sufficient quality, allowing us to define the locations of the putative M1 and M3 ions (fig. S15B). M1 corresponds to one of the putative catalytic magnesium ions $\left(\mathrm{Mg}^{2+}\right)$ in the RNase P-pre-tRNA structure (Fig. 5, A and B) (30), and is coordinated by inner-sphere contacts with the scissile phosphate of ITS1 $_{\mathrm{A} 3}$ and non-bridging phosphoryl oxygens of Nme1 A86 and G87 (Fig. 5A). Although the local density map for M2 is not discrete, we could model a putative $\mathrm{Mg}^{2+}$ ion in the density (fig. S15B), so that it is stabilized by A86, A305 and A306 of Nme1 as well as the O3' leaving group of $\mathrm{A}(-1)$ in the $\mathrm{ITSl}_{\mathrm{A} 3}$ substrate (Fig. 5A), occupying the equivalent position of the other catalytic ion in the RNase P-pre-tRNA structure (Fig. 5, A and B) (30). In contrast to catalytic M1 and M2 ions, the third putative metal ion M3 may play a structural role by mediating contacts with the backbone of Nme1 G87 and the scissile phosphate of ITS1 $_{\mathrm{A} 3}$, helping stabilize the local substrate geometry at the active site (Fig. 5A).

The configuration of this RNA-based catalytic center of RNase MRP is identical to that in the RNase P-pre-tRNA complex, except for the conformation of the conserved uridine in stem P4 of the RNA subunits (Fig. 5, A and B) (30). Upon pre-tRNA binding in RNase $\mathrm{P}$, U93 in Rpr1 rotates a large angle to point into the $\mathrm{P} 4$ stem and interacts with the putative $\mathrm{M} 1 \mathrm{Mg}^{2+}$ ion, transforming the ribozyme into a fully active state (Fig. 5B) (30). In contrast, the corresponding uridine U88 of Nme1 in the RNase MRP-ITS1 ${ }_{\mathrm{A} 3}$ complex structure still maintains a flipped-out conformation (Fig. $5 \mathrm{~A})$. We propose that the snapshot captured in the RNase MRP-ITS1 ${ }_{\mathrm{A} 3}$ complex structure represents a state of initial substrate binding to RNase MRP, in which U88 is still in an inactive conformation (Fig. 5A). Given that less than half of the nucleotides in $\mathrm{ITS1}_{\mathrm{A} 3}$ can be observed in the EM density map, it is possible that the rest of $\operatorname{ITSl}_{\mathrm{A} 3}$, although disordered in the structure, may help induce the conformational change of U88 to fully activate the ribozyme. How RNase MRP is fully activated by $\operatorname{ITSl}_{\mathrm{A} 3}$ warrants future investigations. Thus, although the biochemistry and cryo-EM structure of the RNase MRP-ITS1 ${ }_{\mathrm{A} 3}$ complex reveal clear substrate recognition differences compared to RNase P-pre-tRNA interactions, both essential RNase $\mathrm{P}$ and MRP ribonucleoprotein complexes appear to share a common two metal-ion $\mathrm{S}_{\mathrm{N}}$ 2-type catalytic mechanism (Fig. 5C) $(30,37)$.

\section{Discussion}

In sharp contrast to RNase $\mathrm{P}$ that has a penchant for the tRNA-like fold, it has remained a mystery how RNase MRP recognizes its substrates. So far, only a few RNase MRP substrates have been identified, severely impeding our understanding of RNase MRP function. The short consensus sequence derived from our structural and biochemical studies implies that RNase MRP may have myriad substrates that have not been identified but could play important roles in various cellular contexts. Future work is required to identify and characterize these novel RNase MRP substrates.

Mutations in the RNA component of human RNase MRP causing the highly pleiotropic disease $\mathrm{CHH}$ harkens to 
RNase MRP's essential and irreplaceable role in humans $(20,21)$. Comparative analysis of the RNA components of yeast and human RNase MRP shows that, except for peripheral stems P10, P11 and P15, most of the structural elements in yeast Nme1 RNA are conserved in human RMRP (Fig. 2B and figs. S16 and S17A) (21). Three-dimensional mapping of disease-derived mutations onto the corresponding positions in Nmel structure unveils that, although these incapacitating mutations are found in a wide range of locations in $R M R P$, most of them are spatially clustered in the helical core near the catalytic center of the RNA (fig. S17B). In particular, A70 > G is the most prevalent mutation that has been found in over $90 \%$ of the $\mathrm{CHH}$ patients (21). This adenine nucleotide is conserved in all RNase P and MRP RNAs and forms a key Hoogsteen base-pair with a uracil or cytosine (C250 in human RMRP) in the center of the catalytic pseudoknot (fig. S17C). Structure-based analysis suggests that, although these positions are not directly involved in substrate binding and processing, their mutations very likely induce conformational changes of the RNA, leading to defective substrate binding and processing. Further structural and functional studies of the human RNase MRP holoenzyme will be required to fully understand the effects of these disease mutations.

The structure of yeast RNase MRP explains why RNase MRP is observed in eukaryotes but not in bacteria and archaea $(2,6,43)$. It has long been appreciated that the RNase $\mathrm{P}$ and MRP family of ribonucleases share a common ancestor from the "RNA world", presumably a ribozyme that can catalyze the 5 ' -end maturation of pre-tRNA (44). The overall architecture of this ribozyme has been faithfully succeeded by bacterial and archaeal RNase Ps, in particular the two RNA-based anchors (A-anchor and the T-loop anchor) that can specifically recognize the three-dimensional structure of pre-tRNA through the double-anchor mechanism (Fig. 5D) $(30,37,45)$. It is noteworthy that this high specificity endowed by the RNA anchors, on the other hand, also constrains the ability of bacterial and archaeal RNase Ps to process non-pre-tRNA-like substrates. Although bacteria and archaea had acquired additional protein subunits during evolution (Rpp for bacteria, and (Pop5-Rpp30) ${ }_{2}$ and Rpp29-Rpp21-Rpp38 for archaea), these proteins did not replace the essential function of RNA-based anchors for pretRNA recognition (Fig. 5D) (45-47). The evolution of protein subunits Pop1 and Pop4 in eukaryotic RNase P and MRP released this limitation; Pop1 is a new addition in eukaryotes whereas Pop4 has evolved from its archaeal ancestor Rpp29 with a new N-terminal motif $(48,49)$. In eukaryotic nuclear RNase $\mathrm{P}$, whereas the T-loop anchor has been retained, the A-anchor was replaced by the NTM of Pop1, which folds into a compact module and locks the cleavage site of pre-tRNA in the catalytic center (Fig. 5D) (30). In contrast, RNase MRP had abandoned both RNA-based anchors during evolution, and the NTMs of Pop1 and Pop4 adopt extended conformations that are completely different from those in RNase P (Fig. 5D). Consequently, these refolded motifs together with an RNase MRP specific subunit Rmp1 specifically recognize single-stranded substrates with a short consensus sequence (Fig. 4, A to F, and Fig. 5D). Therefore, the replacement of the rigid RNA-based apparatus by malleable protein subunits Pop1 and Pop4 in eukaryotic RNase P and MRP not only allows eukaryotes to maintain the activity to accurately process pre-tRNA and pre-tRNA-like substrates, but also endows them with the capability of processing much more diversified singlestranded substrates using the same two-metal-ion catalysis mechanism (Fig. 5, C and D).

RNase MRP is one of the two remaining RNA-based RNP catalysts that are found only in eukaryotic cells. The other is spliceosome, which assembles with nuclear premRNAs and splices out the major class of introns (50). But, why is RNase MRP specifically needed, given that there are many proteinaceous endoribonucleases in eukaryotic cells? The known RNA endonucleases either cleave their targets through recognition of specific structures or have very limited or no sequence specificity (51-55). On the other end, some molecular machineries have sequence-specific RNA cleavage activities but require a guide RNA for target recognition (54). A proteinaceous endoribonuclease that can cleave only RNA in a sequence-specific manner has not yet been found. Therefore, the evolution of RNase MRP RNP likely reflects the need to process single-stranded RNAs with sequence specificity in eukaryotes, which contain many more RNA transcripts than bacteria and archaea. The identification and characterization of these RNase MRP substrates will help unveil the in vivo function of this abundant essential RNP.

\section{REFERENCES AND NOTES}

1. R. Karwan, J. L. Bennett, D. A. Clayton, Nuclear RNase MRP processes RNA at multiple discrete sites: Interaction with an upstream $\mathrm{G}$ box is required for subsequent downstream cleavages. Genes Dev. 5, 1264-1276 (1991). doi:10.1101/gad.5.7.1264 Medline

2. M. C. Marvin, D. R. Engelke, Broadening the mission of an RNA enzyme. J. Cell. Biochem. 108, 1244-1251 (2009). doi:10.1002/jcb.22367 Medline

3. O. Esakova, A. S. Krasilnikov, Of proteins and RNA: The RNase P/MRP family. RNA 16, 1725-1747 (2010). doi:10.1261/rna.2214510 Medline

4. W. Yang, Nucleases: Diversity of structure, function and mechanism. Q. Rev. Biophys. 44, 1-93 (2011). doi:10.1017/S0033583510000181 Medline

5. N. Jarrous, V. Gopalan, Archaeal/eukaryal RNase P: Subunits, functions and RNA diversification. Nucleic Acids Res. 38, 7885-7894 (2010). doi:10.1093/nar/gkq701 Medline

6. A. Hernandez-Cid, S. Aguirre-Sampieri, A. Diaz-Vilchis, A. Torres-Larios, Ribonucleases P/MRP and the expanding ribonucleoprotein world. IUBMB Life 64, 521-528 (2012). doi:10.1002/iub.1052 Medline 
7. D. Evans, S. M. Marquez, N. R. Pace, RNase P: Interface of the RNA and protein worlds. Trends Biochem. Sci. 31, 333-341 (2006).

doi:10.1016/i.tibs.2006.04.007 Medline

8. S. Altman, L. A. Kirsebom, in The RNA World, R. Gesteland, T. Cech, J. Atkins, Eds. (Cold Spring Harbor Laboratory Press, 1999), pp. 351-380.

9. S. Chu, R. H. Archer, J. M. Zengel, L. Lindahl, The RNA of RNase MRP is required for normal processing of ribosomal RNA. Proc. Natl. Acad. Sci. U.S.A. 91, 659663 (1994). doi:10.1073/pnas.91.2.659 Medline

10. Z. Lygerou, C. Allmang, D. Tollervey, B. Séraphin, Accurate processing of a eukaryotic precursor ribosomal RNA by ribonuclease MRP in vitro. Science 272. 268-270 (1996). doi:10.1126/science.272.5259.268 Medline

11. L. Lindahl, A. Bommankanti, X. Li, L. Hayden, A. Jones, M. Khan, T. Oni, J. M. Zengel, RNase MRP is required for entry of $35 \mathrm{~S}$ precursor rRNA into the canonical processing pathway. RNA 15, 1407-1416 (2009). doi:10.1261/rna.1302909 Medline

12. M. E. Schmitt, D. A. Clayton, Nuclear RNase MRP is required for correct processing of pre-5.8S rRNA in Saccharomyces cerevisiae. Mol. Cell. Biol. 13 7935-7941 (1993). doi:10.1128/MCB.13.12.7935 Medline

13. T. Gill, T. Cai, J. Aulds, S. Wierzbicki, M. E. Schmitt, RNase MRP cleaves the CLB2 mRNA to promote cell cycle progression: Novel method of mRNA degradation. Mol. Cell. Biol. 24, 945-953 (2004). doi:10.1128/MCB.24.3.945-953.2004 Medline

14. T. Gill, J. Aulds, M. E. Schmitt, A specialized processing body that is temporally and asymmetrically regulated during the cell cycle in Saccharomyces cerevisiae. J. Cell Biol. 173, 35-45 (2006). doi:10.1083/jcb.200512025 Medline

15. K. C. Goldfarb, T. R. Cech, Targeted CRISPR disruption reveals a role for RNase MRP RNA in human preribosomal RNA processing. Genes Dev. 31, 59-71 (2017). doi:10.1101/gad.286963.116 Medline

16. C. T. Thiel, D. Horn, B. Zabel, A. B. Ekici, K. Salinas, E. Gebhart, F. Rüschendorf, H. Sticht, J. Spranger, D. Müller, C. Zweier, M. E. Schmitt, A. Reis, A. Rauch, Severely incapacitating mutations in patients with extreme short stature identify RNA-processing endoribonuclease RMRP as an essential cell growth regulator. Am. J. Hum. Genet. 77, 795-806 (2005). doi:10.1086/497708 Medline

17. N. Jarrous, P. S. Eder, C. Guerrier-Takada, C. Hoog, S. Altman, Autoantigenic properties of some protein subunits of catalytically active complexes of human ribonuclease P. RNA 4, 407-417 (1998). Medline

18. H. Van Eenennaam, J. H. P. Vogelzangs, D. Lugtenberg, F. H. J. Van Den Hoogen, W. J. Van Venrooij, G. J. M. Pruijn, Identity of the RNase MRP- and RNase Passociated Th/To autoantigen. Arthritis Rheum. 46, 3266-3272 (2002). doi:10.1002/art.10673 Medline

19. H. A. Gold, J. N. Topper, D. A. Clayton, J. Craft, The RNA processing enzyme RNase MRP is identical to the Th RNP and related to RNase P. Science 245 , 1377-1380 (1989). doi:10.1126/science.2476849 Medline

20. M. Ridanpää, H. van Eenennaam, K. Pelin, R. Chadwick, C. Johnson, B. Yuan, W. vanVenrooij, G. Pruijn, R. Salmela, S. Rockas, O. Mäkitie, I. Kaitila, A. de la Chapelle, Mutations in the RNA component of RNase MRP cause a pleiotropic human disease, cartilage-hair hypoplasia. Cell 104, 195-203 (2001). doi:10.1016/S0092-8674(01)00205-7 Medline

21. S. Mattijssen, T. J. Welting, G. J. Pruijn, RNase MRP and disease. Wiley Interdiscip. Rev. RNA 1, 102-116 (2010). doi:10.1002/wrna.9 Medline

22. J. R. Chamberlain, Y. Lee, W. S. Lane, D. R. Engelke, Purification and characterization of the nuclear RNase P holoenzyme complex reveals extensive subunit overlap with RNase MRP. Genes Dev. 12, 1678-1690 (1998). doi:10.1101/gad.12.11.1678 Medline

23. T. J. Welting, B. J. Kikkert, W. J. van Venrooij, G. J. Pruijn, Differential association of protein subunits with the human RNase MRP and RNase P complexes. RNA 12, 1373-1382 (2006). doi:10.1261/rna.2293906 Medline

24. M. Dávila López, M. A. Rosenblad, T. Samuelsson, Conserved and variable domains of RNase MRP RNA. RNA Biol. 6, 208-220 (2009). doi:10.4161/rna.6.3.8584 Medline
25. O. Esakova, A. Perederina, C. Quan, M. E. Schmitt, A. S. Krasilnikov, Footprinting analysis demonstrates extensive similarity between eukaryotic RNase $P$ and RNase MRP holoenzymes. RNA 14, 1558-1567 (2008). doi:10.1261/rna.1106408 Medline

26. X. Li, D. N. Frank, N. Pace, J. M. Zengel, L. Lindahl, Phylogenetic analysis of the structure of RNase MRP RNA in yeasts. RNA 8, 740-751 (2002). doi:10.1017/S1355838202022082 Medline

27. Y. Zhu, V. Stribinskis, K. S. Ramos, Y. Li, Sequence analysis of RNase MRP RNA reveals its origination from eukaryotic RNase P RNA. RNA 12, 699-706 (2006). doi:10.1261/rna.2284906 Medline

28. S. C. Walker, D. R. Engelke, Ribonuclease P: The evolution of an ancient RNA enzyme. Crit. Rev. Biochem. Mol. Biol. 41, 77-102 (2006). doi:10.1080/10409230600602634 Medline

29. O. Esakova, A. Perederina, I. Berezin, A. S. Krasilnikov, Conserved regions of ribonucleoprotein ribonuclease MRP are involved in interactions with its substrate. Nucleic Acids Res. 41, 7084-7091 (2013). doi:10.1093/nar/gkt432 Medline

30. P. Lan, M. Tan, Y. Zhang, S. Niu, J. Chen, S. Shi, S. Qiu, X. Wang, X. Peng, G. Cai, H. Cheng, J. Wu, G. Li, M. Lei, Structural insight into precursor tRNA processing by yeast ribonuclease P. Science 362 , eaat6678 (2018). doi:10.1126/science.aat6678 Medline

31. K. Salinas, S. Wierzbicki, L. Zhou, M. E. Schmitt, Characterization and purification of Saccharomyces cerevisiae RNase MRP reveals a new unique protein component. J. Biol. Chem. 280, 11352-11360 (2005). doi:10.1074/ibc.M409568200 Medline

32. O. Esakova, A. Perederina, C. Quan, I. Berezin, A. S. Krasilnikov, Substrate recognition by ribonucleoprotein ribonuclease MRP. RNA 17, 356-364 (2011). doi:10.1261/rna.2393711 Medline

33. A. Perederina, O. Esakova, C. Quan, E. Khanova, A. S. Krasilnikov, Eukaryotic ribonucleases P/MRP: The crystal structure of the P3 domain. EMBO J. 29, 761769 (2010). doi:10.1038/emboj.2009.396 Medline

34. J. Wu, S. Niu, M. Tan, C. Huang, M. Li, Y. Song, Q. Wang, J. Chen, S. Shi, P. Lan, M. Lei, Cryo-EM Structure of the Human Ribonuclease P Holoenzyme. Cell 175, 1393-1404.e11 (2018). doi:10.1016/i.cell.2018.10.003 Medline

35. A. V. Kazantsev, A. A. Krivenko, D. J. Harrington, S. R. Holbrook, P. D. Adams, N. R. Pace, Crystal structure of a bacterial ribonuclease P RNA. Proc. Natl. Acad. Sci. U.S.A. 102, 13392-13397 (2005). doi:10.1073/pnas.0506662102 Medline

36. A. Torres-Larios, K. K. Swinger, A. S. Krasilnikov, T. Pan, A. Mondragón, Crystal structure of the RNA component of bacterial ribonuclease P. Nature 437, 584587 (2005). doi:10.1038/nature04074 Medline

37. N. J. Reiter, A. Osterman, A. Torres-Larios, K. K. Swinger, T. Pan, A. Mondragón, Structure of a bacterial ribonuclease $P$ holoenzyme in complex with tRNA. Nature 468, 784-789 (2010). doi:10.1038/nature09516 Medline

38. X. Li, S. Zaman, Y. Langdon, J. M. Zengel, L. Lindahl, Identification of a functional core in the RNA component of RNase MRP of budding yeasts. Nucleic Acids Res. 32, 3703-3711 (2004). doi:10.1093/nar/gkh689 Medline

39. A. S. Krasilnikov, X. Yang, T. Pan, A. Mondragón, Crystal structure of the specificity domain of ribonuclease P. Nature 421, 760-764 (2003). doi:10.1038/nature01386 Medline

40. A. S. Krasilnikov, Y. Xiao, T. Pan, A. Mondragón, Basis for structural diversity in homologous RNAs. Science 306, 104-107 (2004). doi:10.1126/science.1101489 Medline

41. A. Perederina, E. Khanova, C. Quan, I. Berezin, O. Esakova, A. S. Krasilnikov, Interactions of a Pop5/Rpp1 heterodimer with the catalytic domain of RNase MRP. RNA 17, 1922-1931 (2011). doi:10.1261/rna.2855511 Medline

42. J. Aulds, S. Wierzbicki, A. McNairn, M. E. Schmitt, Global identification of new substrates for the yeast endoribonuclease, RNase mitochondrial RNA processing (MRP). J. Biol. Chem. 287, 37089-37097 (2012). doi:10.1074/jbc.M112.389023 Medline

43. V. Gopalan, N. Jarrous, A. S. Krasilnikov, Chance and necessity in the evolution of 
RNase P. RNA 24, 1-5 (2018). doi:10.1261/rna.063107.117 Medline

44. L. B. Lai, A. Vioque, L. A. Kirsebom, V. Gopalan, Unexpected diversity of RNase P, an ancient tRNA processing enzyme: Challenges and prospects. FEBS Lett. 584, 287-296 (2010). doi:10.1016/i.febslet.2009.11.048 Medline

45. F. Wan, Q. Wang, J. Tan, M. Tan, J. Chen, S. Shi, P. Lan, J. Wu, M. Lei, Cryoelectron microscopy structure of an archaeal ribonuclease P holoenzyme. Nat. Commun. 10, 2617 (2019). doi:10.1038/s41467-019-10496-3 Medline

46. W. Y. Chen, D. K. Pulukkunat, I. M. Cho, H. Y. Tsai, V. Gopalan, Dissecting functional cooperation among protein subunits in archaeal RNase P, a catalytic ribonucleoprotein complex. Nucleic Acids Res. 38, 8316-8327 (2010). doi:10.1093/nar/gkg668 Medline

47. M. Kimura, Structural basis for activation of an archaeal ribonuclease P RNA by protein cofactors. Biosci. Biotechnol. Biochem. 81, 1670-1680 (2017). doi:10.1080/09168451.2017.1353404 Medline

48. E. Hartmann, R. K. Hartmann, The enigma of ribonuclease P evolution. Trends Genet. 19, 561-569 (2003). doi:10.1016/i.tig.2003.08.007 Medline

49. M. A. Rosenblad, M. D. López, P. Piccinelli, T. Samuelsson, Inventory and analysis of the protein subunits of the ribonucleases $P$ and MRP provides further evidence of homology between the yeast and human enzymes. Nucleic Acids Res. 34, 5145-5156 (2006). doi:10.1093/nar/gkl626 Medline

50. J. A. Doudna, T. R. Cech, The chemical repertoire of natural ribozymes. Nature 418, 222-228 (2002). doi:10.1038/418222a Medline

51. J. Houseley, D. Tollervey, The many pathways of RNA degradation. Cell 136, 763776 (2009). doi:10.1016/j.cell.2009.01.019 Medline

52. K. Januszyk, C. D. Lima, The eukaryotic RNA exosome. Curr. Opin. Struct. Biol. 24, 132-140 (2014). doi:10.1016/i.sbi.2014.01.011 Medline

53. D. L. Court, J. Gan, Y.-H. Liang, G. X. Shaw, J. E. Tropea, N. Costantino, D. S. Waugh, X. Ji, RNase III: Genetics and function; structure and mechanism. Annu. Rev. Genet. 47, 405-431 (2013). doi:10.1146/annurev-genet-110711-155618 Medline

54. R. C. Wilson, J. A. Doudna, Molecular mechanisms of RNA interference. Annu. Rev. Biophys. 42, 217-239 (2013). doi:10.1146/annurev-biophys-083012$\underline{130404}$ Medline

55. D. L. Makino, F. Halbach, E. Conti, The RNA exosome and proteasome: Common principles of degradation control. Nat. Rev. Mol. Cell Biol. 14, 654-660 (2013). doi:10.1038/nrm3657 Medline

56. R. D. Gietz, R. H. Schiestl, Quick and easy yeast transformation using the LiAc/SS carrier DNA/PEG method. Nat. Protoc. 2, 35-37 (2007). doi:10.1038/nprot.2007.14 Medline

57. C. Janke, M. M. Magiera, N. Rathfelder, C. Taxis, S. Reber, H. Maekawa, A. Moreno-Borchart, G. Doenges, E. Schwob, E. Schiebel, M. Knop, A versatile toolbox for PCR-based tagging of yeast genes: New fluorescent proteins, more markers and promoter substitution cassettes. Yeast 21, 947-962 (2004). doi:10.1002/yea.1142 Medline

58. K. Hipp, K. Galani, C. Batisse, S. Prinz, B. Böttcher, Modular architecture of eukaryotic RNase P and RNase MRP revealed by electron microscopy. Nucleic Acids Res. 40, 3275-3288 (2012). doi:10.1093/nar/gkr1217 Medline

59. S. Q. Zheng, E. Palovcak, J.-P. Armache, K. A. Verba, Y. Cheng, D. A. Agard, MotionCor2: Anisotropic correction of beam-induced motion for improved cryoelectron microscopy. Nat. Methods 14, 331-332 (2017). doi:10.1038/nmeth.4193 Medline

60. K. Zhang, Gctf: Real-time CTF determination and correction. J. Struct. Biol. 193, 1-12 (2016). doi:10.1016/j.jsb.2015.11.003 Medline

61. J. Zivanov, T. Nakane, B. O. Forsberg, D. Kimanius, W. J. H. Hagen, E. Lindahl, S. H. W. Scheres, New tools for automated high-resolution cryo-EM structure determination in RELION-3. eLife 7, e42166 (2018). doi:10.7554/eLife.42166 Medline

62. P. Emsley, K. Cowtan, Coot: Model-building tools for molecular graphics. Acta Crystallogr. D 60, 2126-2132 (2004). doi:10.1107/S0907444904019158
Medline

63. K. Oshima, X. Gao, S. Hayashi, T. Ueda, T. Nakashima, M. Kimura, Crystal structures of the archaeal RNase P protein Rpp38 in complex with RNA fragments containing a K-turn motif. Acta Crystallogr. F 74, 57-64 (2018). doi:10.1107/S2053230X17018039 Medline

64. P. D. Adams, P. V. Afonine, G. Bunkóczi, V. B. Chen, I. W. Davis, N. Echols, J. J. Headd, L.-W. Hung, G. J. Kapral, R. W. Grosse-Kunstleve, A. J. McCoy, N. W. Moriarty, R. Oeffner, R. J. Read, D. C. Richardson, J. S. Richardson, T. C. Terwilliger, P. H. Zwart, PHENIX: A comprehensive Python-based system for macromolecular structure solution. Acta Crystallogr. D 66, 213-221 (2010). doi:10.1107/S0907444909052925 Medline

65. I. W. Davis, A. Leaver-Fay, V. B. Chen, J. N. Block, G. J. Kapral, X. Wang, L. W. Murray, W. B. Arendall 3rd, J. Snoeyink, J. S. Richardson, D. C. Richardson, MolProbity: All-atom contacts and structure validation for proteins and nucleic acids. Nucleic Acids Res. 35, W375-W383 (2007). doi:10.1093/nar/gkm216 Medline

66. W. DeLano, The PyMOL Molecular Graphics System; www.pymol.org. (2002).

67. E. F. Pettersen, T. D. Goddard, C. C. Huang, G. S. Couch, D. M. Greenblatt, E. C. Meng, T. E. Ferrin, UCSF Chimera-A visualization system for exploratory research and analysis. J. Comput. Chem. 25, 1605-1612 (2004). doi:10.1002/jcc.20084 Medline

\section{ACKNOWLEDGMENTS}

We thank the staff members of the Electron Microscopy System and Mass Spectrometry System at Shanghai Institute of Precision Medicine for providing technical support and assistance in data collection. Funding: This work was supported by grants from the National Natural Science Foundation of China (31525007 and 31930063 to M.L., 31900929 and U1932114 to P.L.), Shanghai Municipal Education Commission Gaofeng Clinical Medicine Grant Support (20181711 to J.W.), the Shanghai Sailing Program (19YF1425400 to P.L.), the Young Elite Scientist Sponsorship Program of China Association for Science and Technology (2018QNRC001 to P.L.). Author contributions: P.L. and B.Z. purified the RNase MRP complex. P.L., M.T., M.C., B.Z., and S.L. prepared cryo-EM specimens, collected data sets and determined the structure. J.W carried out model building and refinement. P.L and B.Z. carried out biochemical analysis. All authors contributed to data interpretation and the writing of the manuscript. M.L. and P.L. wrote the manuscript. M.L., P.L. and J.W. initiated and orchestrated the project. The authors declare no competing financial interests. Competing interests: The authors declare no competing interests. Data and materials availability: The cryo-EM 3D maps of yeast RNase MRP alone and in complex with ITS1 ${ }_{A 3}$ were deposited in EMDB database with accession code EMD30296 and EMD-30297, respectively. The atomic models of yeast RNase MRP alone and in complex with ITS1 ${ }_{\mathrm{A} 3}$ were deposited in PDB database with accession code 7C79 and 7C7A, respectively. All other data needed to evaluate the conclusions in the paper are found in the main text or supplementary materials.

\section{SUPPLEMENTARY MATERIALS}

science.sciencemag.org/cgi/content/full/science.abc0149/DC1

Materials and Methods

Figs. S1 to S17

Tables S1 and S2

References (56-67)

MDAR Reproducibility Checklist

1 April 2020; accepted 11 June 2020

Published online 25 June 2020

10.1126/science.abc0149 


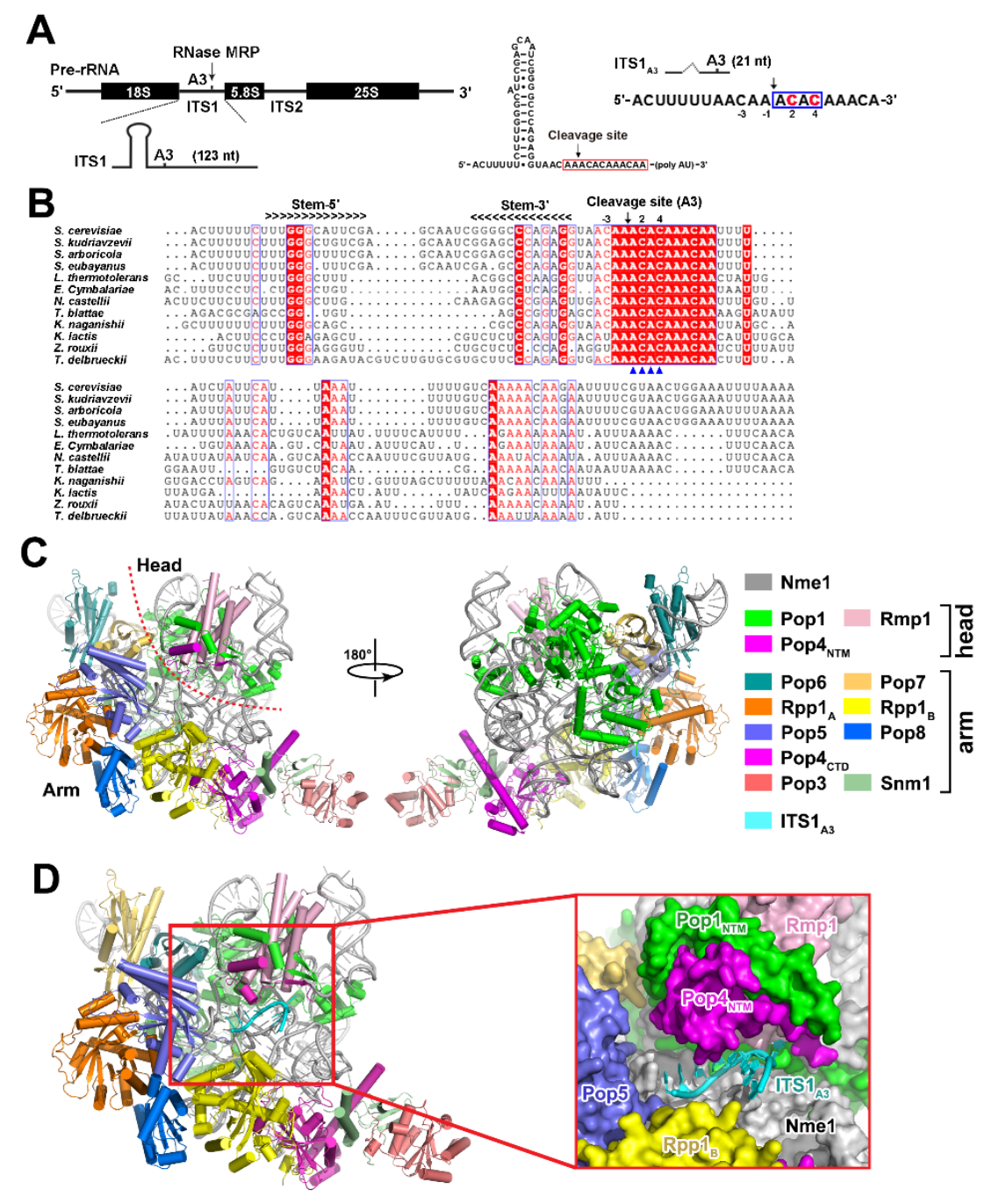

Figure 1

Fig. 1. Overall structures of the $S$. cerevisiae RNase MRP holoenzyme alone and in complex with the ITS1 $1_{A 3}$ substrate. (A) Schematic diagram of the S. cerevisiae 35S pre-rRNA transcript. Mature rRNAs and spacers are shown as black boxes and lines, respectively, along with predicted secondary structure of the 5'-stem in ITS1. The numbering scheme of the $\mathrm{A} 3$ cleavage site is shown under the sequence of $I T S 1_{A 3}$, and the consensus recognition sequence is boxed with C2 and C4 colored in red. (B) Multiple sequence alignment of the ITS1 region from representative species (Saccharomyces cerevisiae; Saccharomyces kudriavzevii; Saccharomyces arboricola; Saccharomyces eubayanus; Lachancea thermotolerans; Eremothecium cymbalariae; Naumovozyma castellii: Tetrapisispora blattae; Kazachstania naganishii; Kluyveromyces lactis; Zygosaccharomyces rouxii; Torulaspora delbrueckii) in Saccharomycetaceae. Nucleotides important for substrate recognition are highlighted by blue triangles. (C) Front and back views of the overall structure of the S. cerevisiae RNase MRP complex. The protein and RNA subunits of RNase MRP are shown in cartoon representation and colored according to the scheme shown on the right. The boundary between the head and arm modules in the protein hook is denoted by a red dashed line. (D) Overall structure of the S. cerevisiae RNase MRP in complex with the single-stranded ITS1 $1_{A 3}$ substrate. The RNase MRP complex and the ITS1 $1_{A 3}$ substrate are shown in cartoon and colored as in (C). A close-up view of the substrate-binding pocket is shown in surface representation on the right. Pop $1_{\mathrm{NTM}}$ and Pop4 $4_{\mathrm{NTM}}$ : N-terminal motifs of Pop1 and Pop4. 

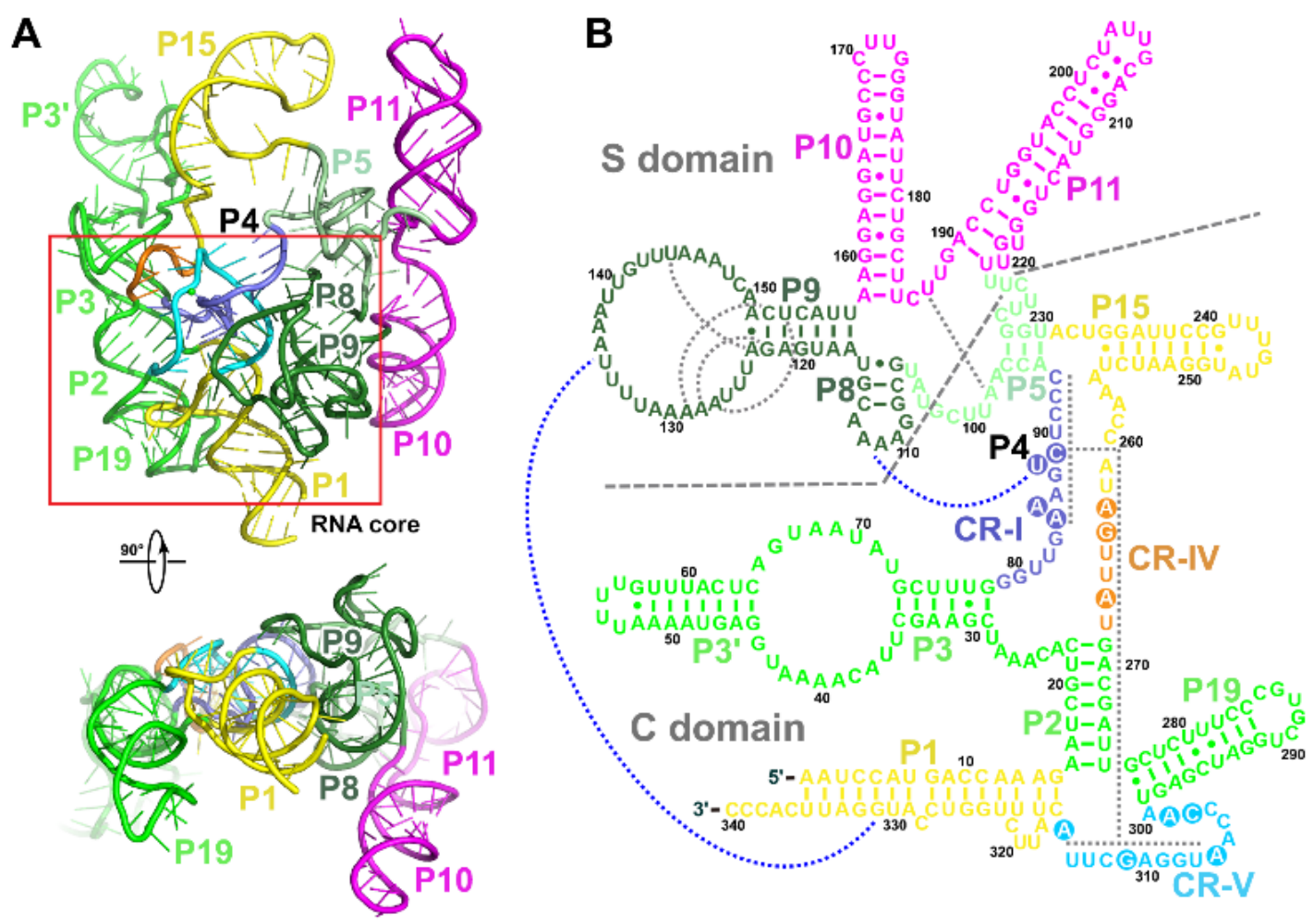

Fig. 2. Structure of the Nme1 RNA. (A) Two orthogonal views of the overall structure of the Nme1 RNA. CR-I, CRIV and CR-V are colored in slate, orange and cyan, respectively. The helical RNA core is highlighted by a red box. (B) Secondary structure diagram of the Nmel RNA. The canonical Watson-Crick and non-canonical base-pairing interactions are shown as solid lines and dots, respectively. The long-range base-pairing and tertiary interactions are denoted as black and blue dotted lines, respectively. Nucleotides that are universally conserved in all known MRP RNAs are highlighted with shaded circles. 
A

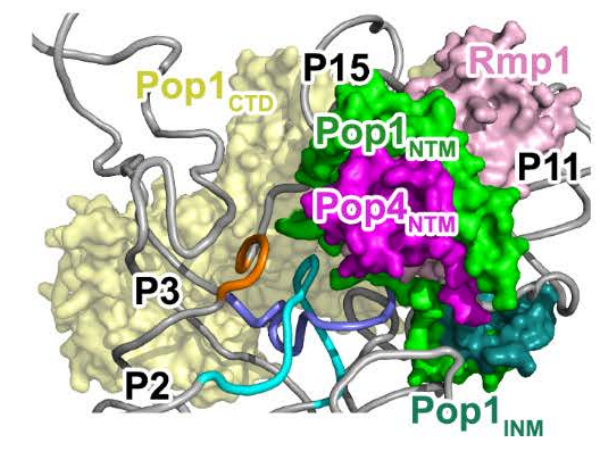

C

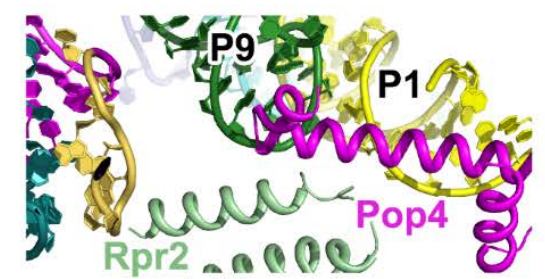

RNase P

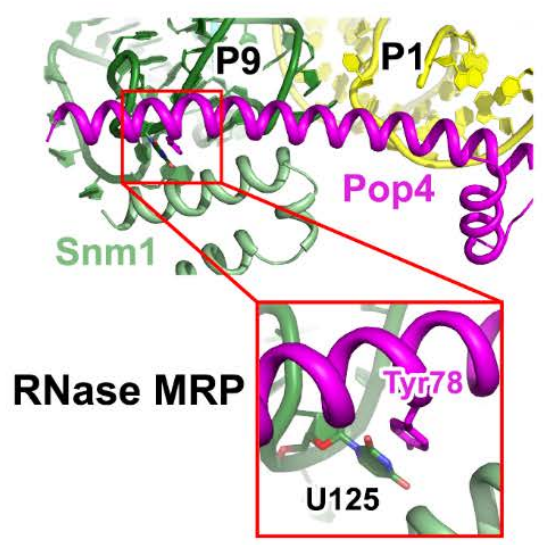

B

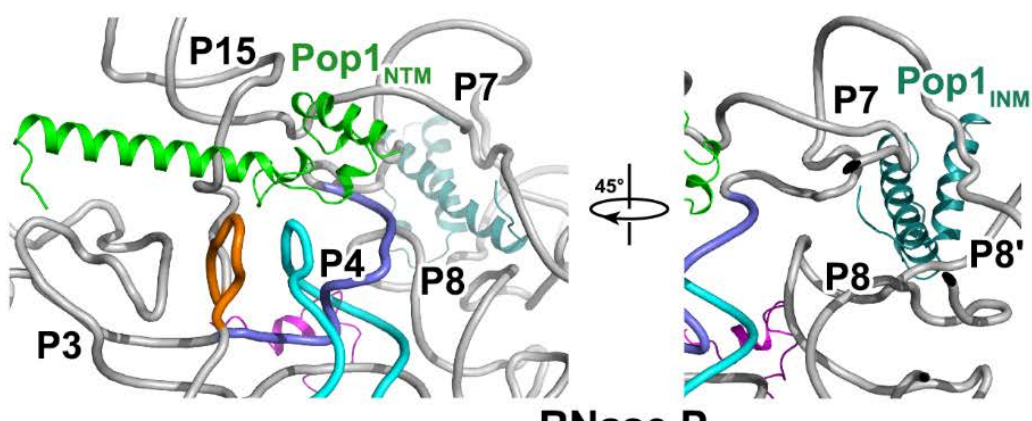

\section{RNase P}
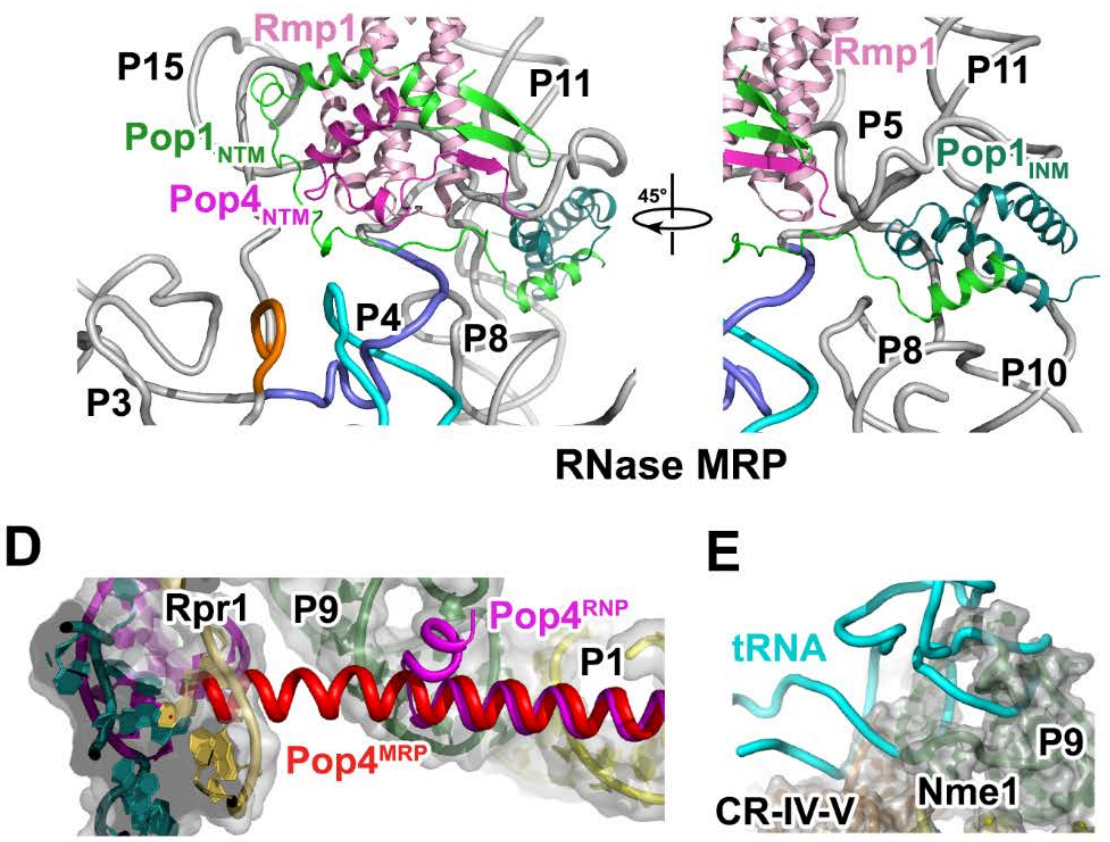

Fig. 3. Protein subunits and their interaction with Nme1. (A) Interface between the protein head module and the Nme1 RNA. Pop1 $1_{\text {INm: internal motif of Pop1; Pop1 }}$ стD: C-terminal domain of Pop1. (B) Structural comparison of the protein head modules in S. cerevisiae RNase P (top) and RNase MRP (bottom) in two related views reveals the refolding of Pop1 $1_{\mathrm{NTM}}$, Pop1 $1_{\mathrm{NM}}$ and Pop4 $4_{\mathrm{NTM}}$ in the two complexes. (C) Close-up view of the Pop4 helix in RNase P (top) and RNase MRP (bottom) bound to its corresponding RNA subunits Rpr1 and Nme1, respectively. Inset: close-up view of the stacking interaction between Pop4 ${ }^{\mathrm{Y78}}$ and U125 of Nme1. (D) The Pop4 helix in RNase MRP (red) would have a collision with the CR-II-III T loop structure when RNase MRP is superposed onto RNase P based on their RNA components. Only the Pop4 helix in RNase P (in magenta) and in RNase MRP (red) as well as the RNase P Rpr1 RNA are shown for clarity. (E) Structural superposition analysis of RNase $P$ and RNase MRP reveals that the pre-tRNA substrate in RNase P has a collision with stem P9 of Nme1 in RNase MRP. Only the Nme1 RNA of RNase MRP and the pre-tRNA substrate are shown for clarity. 
A

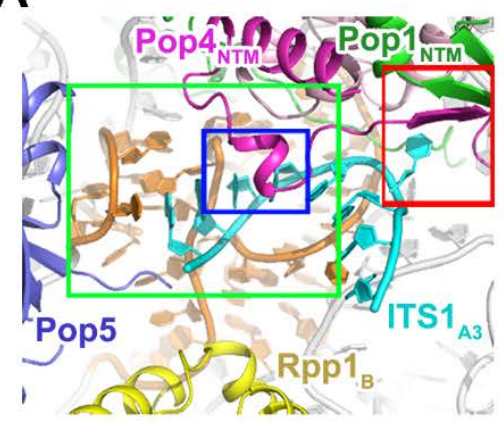

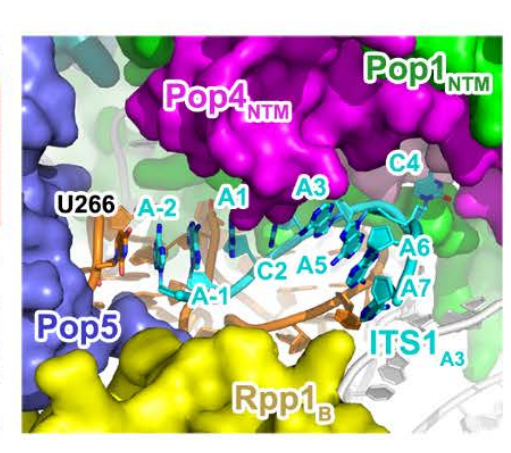

B

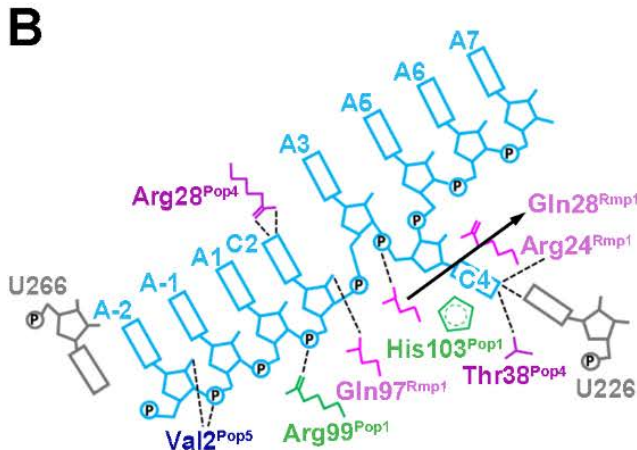

E

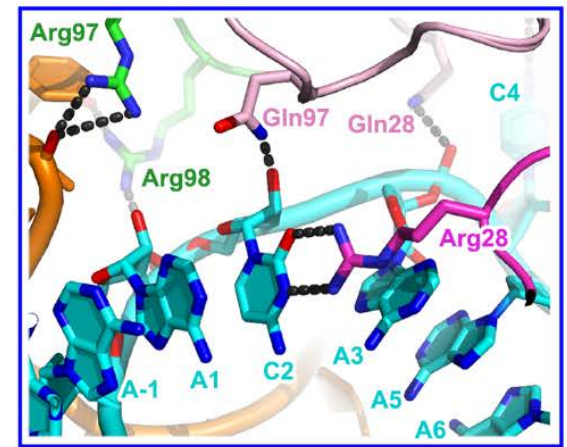

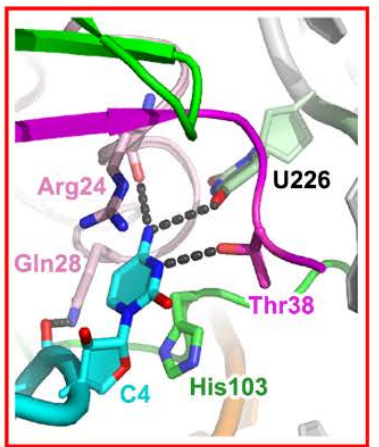
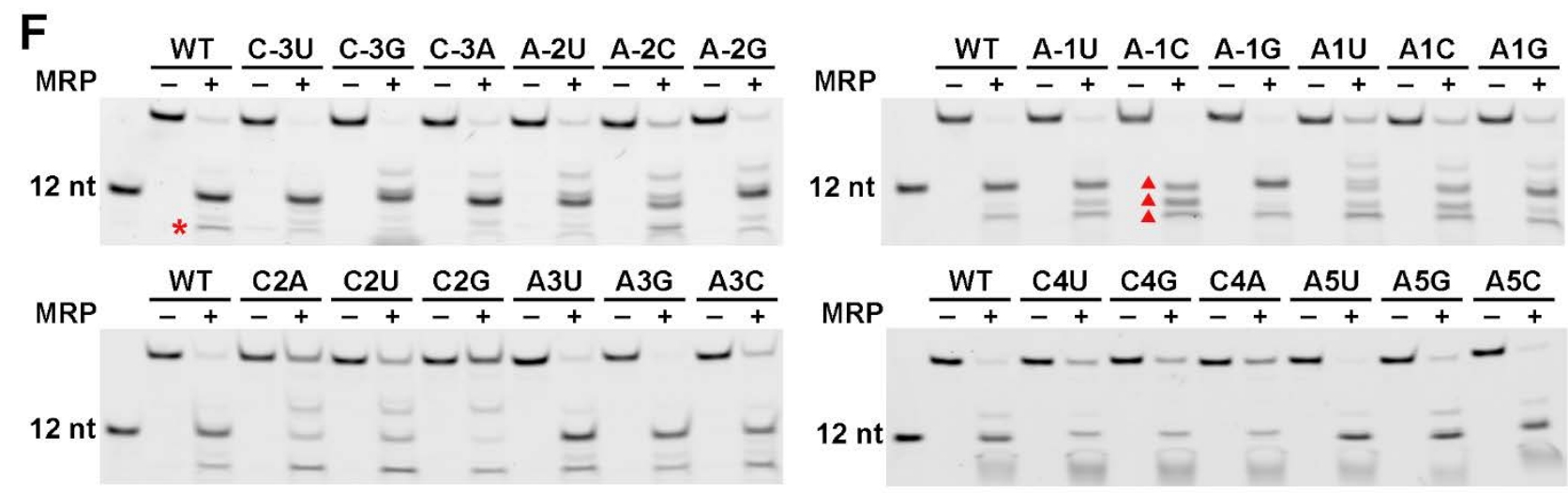

Fig. 4. Substrate recognition by RNase MRP. (A) The ITS1 $1_{\mathrm{A} 3}$ substrate adopts a deformed helical conformation and is accommodated deeply in the substrate-binding groove. The ITS1 $1_{\mathrm{A}}$-binding groove is shown in ribbon (left) and surface (right) representation and colored as in Fig. 1C. The ITS1 $1_{\mathrm{A} 3}$ substrate is shown in cartoon and colored in cyan. Base stacking interaction, recognitions of $\mathrm{C} 2$ and $\mathrm{C} 4$ are highlighted in green, blue and red boxes, respectively; enlarged in (C) to (E). (B) Schematic diagram of the RNase MRP-ITS1 $1_{\mathrm{A3}}$ interaction. Nucleotides in ITS1 $1_{A 3}$ and Nme1 are shown in cyan and gray, respectively. Residues in Pop1, Pop4, Rmp1 and Pop5 are colored as in Fig. 1C. Hydrogen bonds and electrostatic interactions are denoted as black dashed lines. (C) Close-up view of the stacking interactions among the nucleotide bases in ITS1 $1_{\mathrm{A} 3}$ and between ITS1 $1_{\mathrm{A}}$ and U266 in CR-IV of Nme1. (D) Detailed interactions of ITS1 $1_{\mathrm{A3}} \mathrm{C} 2$ with Pop4 ${ }^{\mathrm{Arg} 28}$ and Rmp1 ${ }^{\mathrm{GIn} 97}$. (E) ITS1 $1_{\mathrm{A3}} \mathrm{C} 4$ flips into a pocket formed by Pop1 $1_{\mathrm{NTM}}$, Pop4 $_{\text {NTM }}$, Rmp1 and the Nme1 RNA. (F) In vitro cleavage activity assay of wild-type and single-nucleotide substituted ITS1 $1_{\mathrm{A} 3}$ substrates. A 12-nucleotide oligo was used as a marker for the correctly processed product by RNase MRP. A minor cleavage between $A(-5)$ and $A(-4)$ is denoted with a red star. Three equal-amount cleavage products due to the A-to- $C$ substitution at position -1 are denoted with red triangles. 

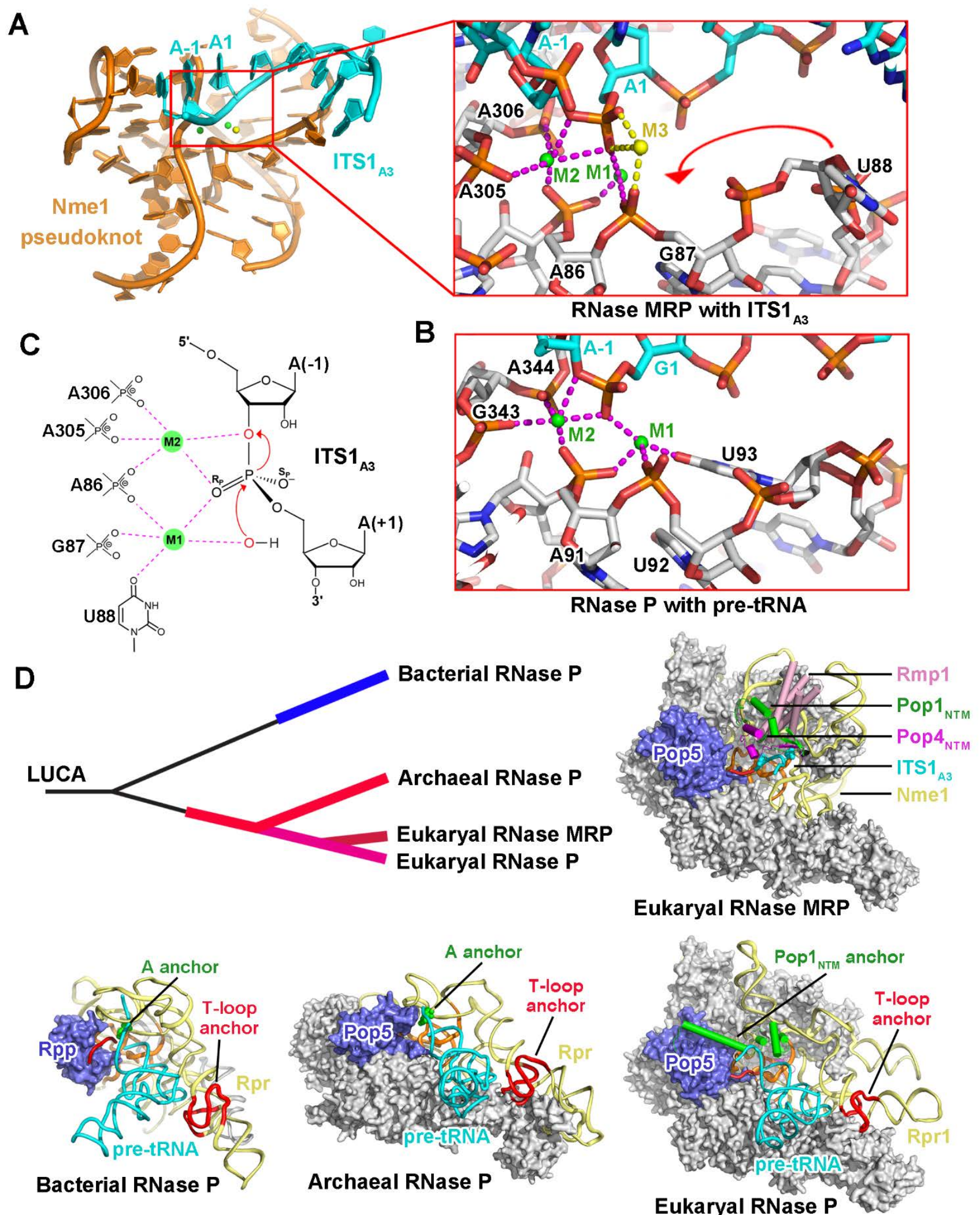
Fig. 5 (preceding page). Implications for catalysis and evolution of RNase MRP. (A) Left: Overview of the catalytic center in yeast RNase MRP. The pseudoknot of Nme1 and the ITS1 $1_{\mathrm{A}}$ substrate are colored in orange and cyan, respectively. Right inset: A close-up view of the catalytic center. The coordination of modeled ions M1 and M2 is highlighted in magenta dashed lines and that of M3 in yellow dashed lines. The conserved nucleotide U88 of Nme1 flips out and points away from the catalytic center in the complex structure. (B) A close-up view of the catalytic center in yeast RNase P (PDB: 6AH3) (30). Coordination of modeled ions M1 and M2 are essentially identical to those in RNase MRP except for nucleotide U93. In presence of the pre-tRNA substrate, the corresponding conserved nucleotide U93 points into the catalytic center to coordinate the M1 metal ion. (C) Proposed reaction mechanism for the processing of ITS1 $1_{A 3}$ by yeast RNase MRP. The reactive oxygens are colored in red, the ITS1 $1_{\mathrm{A} 3}$ scissile phosphate is depicted in a pre-attack state, and the interactions between catalytically important nucleotides and reactive oxygens mediated by modeled ions $\mathrm{M} 1$ and $\mathrm{M} 2$ are shown as magenta dashed lines. M1 coordinates an attacking hydroxyl nucleophile during the cleavage reaction. (D) A schematic cladogram depicting the possible evolution pathway of RNase P and RNase MRP is shown at upper-left (LUCA: last universal common ancestor). Proteins that mainly function to stabilize the catalytic RNA subunit and adopt similar architectures in both RNase $P$ and RNase MRP are shown in grey surface. Single-stranded regions $5^{\prime}$ to the cleavage site in pre-tRNA and ITS1 $1_{\mathrm{A}}$ are colored in red and the rest of the substrates in cyan. 